\title{
OPTIMASI PEMANFAATAN SUMBERDAYA IKAN KARANG HIDUP KONSUMSI (LIFE REEF FISH FOR FOOD / LRFF) DI PERAIRAN KEPULAUAN SPERMONDE, SULAWESI SELATAN*
}

\author{
Oleh: \\ Benny Osta Nababan dan Yesi Dewita Sari**
}

\begin{abstract}
ABSTRAK
Penelitian ini bertujuan untuk mengetahui tingkat pemanfaatan dan menentukan tingkat optimal pemanfataan sumberdaya LRFF di perairan Kepulauan Spermonde. Penelitian ini dilakukan di perairan Kepulauan Spermonde, Sulawesi Selatan. Penelitian ini menggunakan model surplus produksi dengan fungsi pertumbuhan logistik. Model pengelolaan dilihat dari rezim maximum economi yield, maximum sustainable yield dan open access. Hasil penelitian menunjukkan bahwa nilai biomas optimal pada rezim maximum economic yield (MEY) adalah 5.120 ton, tingkat produksi optimal adalah 1.047 ton dan jumlah effort (trip) optimal yang diperbolehkan adalah 284.792 trip. Pada rezim maximum sustainable yield (MSY) biomas, produksi dan upaya lestari adalah berturut-turut 4.154 ton, 1.107 ton dan 371.128 trip. Rezim akses terbuka biomas maksimum hanya 1.933 ton, produksi maksimum yang dapat diperoleh sebesar 790 ton dan jumlah trip maksimum yang diperbolehkan 569.584 trip. Rente ekonomi yang diperoleh jika menerapkan rezim MEY adalah Rp 41.587.148.882, rezim MSY adalah Rp 37.765.171.742 dan rezim open access adalah Rp.0. Pemanfaatan sumberdaya LRFF di Kepulauan Spermonde telah terjadi overfishing karena diketahui produksi aktual lebih tinggi daripada produksi optimal yang disarankan. Oleh karena itu diperlukan pengelolaan perikanan sumberdaya LRFF yang mengarah kondisi optimal agar dalam jangka panjang pemanfaatan sumberdaya LRFF tetap lestari.
\end{abstract}

Kata Kunci : Optimasi, Pemanfaatan, Pengelolaan Perikanan, Ikan Karang Hidup Konsumsi (LRFF), Kepulauan Spermonde

\section{Abstract : Optimal Exploitation Of Life Reef Fish For Food (LRFF) In The Spermonde Islands Of South Sulawesi. By: Benny Osta Nababan and Yesi Dewita Sari}

This research aimed to understand about the LRFF resources exploitation rate and its optimal used in the Spermonde Islands. The research was conducted in Spermonde Island of South Sulawesi. This research was used surplus production model with logistic growth function. Management model of LRFF resources based on maximum economic yield, maximum sustainable yield and open access regimes. Results showed that optimal biomass, optimal production and optimal effort at maximum economic yield were obtained at 5.120 ton, 1.047 ton and 284.792 trip. Sustainable biomass, productions and effort at maximum sustainable yield were 4.154 ton, 1.107 ton and 371.128 trip. Maximum biomass, productions and effort at open access were 1.933 ton, 790 ton and 569.584 trip. Economic rent obtained if applying regime of MEY was Rp 41.587.148.882, regime MSY was Rp 37.765.171.742 and regime open access was Rp.0. Exploitation of LRFF at Spermonde Island had indicated over fishing, because actual productions was greater than optimal productions. Therefore, on optimal management of LRFF fisheries resource is required to ensure long-term sustainability of the LRFF

Keywords : Optimization, Exploitation, Fisheries Management, Life Reef Fish Food (LRFF), Spermonde Island

\footnotetext{
* Makalah ini adalah bagian dari Tesis Magister Sain pada Bidang Ekonomi Sumber Daya Tropika, Institut Pertanian Bogor. Bogor

** Peneliti Pada Balai Besar Riset Sosial Ekonomi Kelautan dan Perikanan, BRKP-DKP.

JI. KS TUBUN Petamburan VI Slipi Jakarta 10260. Telp. (021) 53650159
} 


\section{PENDAHULUAN}

Salah satu komoditas perikanan yang menjadi permintaan pasar luar negeri adalah ikan karang hidup konsumsi atau yang lebih dikenal Life Reef Fish for Food (LRFF). Permintaan terhadap ikan karang konsumsi ini tidak sepenuhnya dapat dipenuhi dari produksi hasil tangkapan ikan karang di Indonesia. Walaupun jumlah hasil tangkapan yang di ekspor telah mengalami peningkatan yang sangat besar. Menurut Departemen Kelautan dan Perikanan (2003), ekspor ikan karang konsumsi mengalami peningkatan dari 300 ton pada tahun 1989 menjadi 3.800 ton pada tahun 1995. Indonesia kini merupakan salah satu negara pengekspor utama ikan karang konsumsi di Asia. Pasar utama ikan karang hidup konsumsi dari Indonesia adalah Hongkong.

Permintaan yang tinggi diiringi dengan harga yang terus meningkat dibandingkan jenis ikan lainnya mendorong pelaku usaha perikanan untuk meningkatkan suplai melalui peningkatan jumlah hasil tangkapan. Peningkatan jumlah hasil tangkapan dapat dilakukan dengan berbagai cara antara lain dengan cara menambah jumlah armada penangkapan, menambah jumlah nelayan, meningkatkan jumlah trip atau mencari/ memperluas wilayah penangkapan. Peningkatan jumlah hasil tangkapan ini memberikan tekanan yang semakin tinggi terhadap pemanfaatan sumberdaya ikan karang hidup konsumsi. Peningkatan jumlah hasil tangkapan tidak dapat terus dilakukan karena sumberdaya perikanan juga mengalami keterbatasan dalam melakukan reproduksi walaupun sumberdaya perikanan termasuk jenis sumberdaya yang dapat pulih.

Pemanfaatan sumberdaya ikan karang hidup konsumsi di perairan Kepulauan Spermonde mengalami permintaan yang sangat tinggi sejak tahun 1995 hingga kini dan berpotensi menimbulkan tangkap lebih (overfishing), sehingga sumberdaya ikan karang hidup konsumsi ini menjadi tidak berkelanjutan. Oleh karena itu dalam pemanfaatan sumberdaya perikanan diperlukan adanya pengelolaan sehingga pemanfaatan dapat terus dilakukan.

Pengelolaan sumberdaya perikanan atau ikan karang hidup konsumsi dilakukan supaya tingkat pemanfaatan dapat dilakukan pada kondisi yang optimal. Penelitian ini dilakukan untuk mengetahui seberapa besar tingkat pemanfaatan sumberdaya ikan karang hidup konsumsi yang telah dilakukan di Perairan Kepulauan Spermonde dan juga berapa tingkat optimal pemanfaatan yang dapat dilakukan. Riset ini bertujuan untuk mengetahui tingkat pemanfaatan sumberdaya ikan karang hidup konsumsi di Kepulauan Spermonde dan menentukan tingkat optimal pemanfaatan sumberdaya ikan karang hidup konsumsi di Kepulauan Spermonde, Sulawesi Selatan.

\section{METODE}

\section{Lokasi dan Waktu Riset}

Riset optimasi pemanfaatan sumberdaya ikan karang hidup konsumsi ini dilakukan di perairan Kepulauan Spermonde, Sulawesi Selatan. Peta lokasi penelitian disajikan pada Gambar 1. Penelitian ini dimulai pada Bulan Nopember 2005 sampai dengan Bulan Januari 2006.

\section{Kerangka Pendekatan}

Perairan Spermonde kaya akan sumberdaya ikan-ikan karang. Sumberdaya ikan-ikan karang inilah yang menjadi mata pencaharian nelayan setempat untuk menangkap sumberdaya ikan karang tersebut hidup-hidup untuk konsumsi dan ekspor (ikan karang hidup konsumsi). Dalam melakukan analisis optimasi sumberdaya ikan karang hidup konsumsi di Kepulauan Spermonde dilakukan pengumpulan data baik untuk data biologi maupun data ekonomi, sehingga 


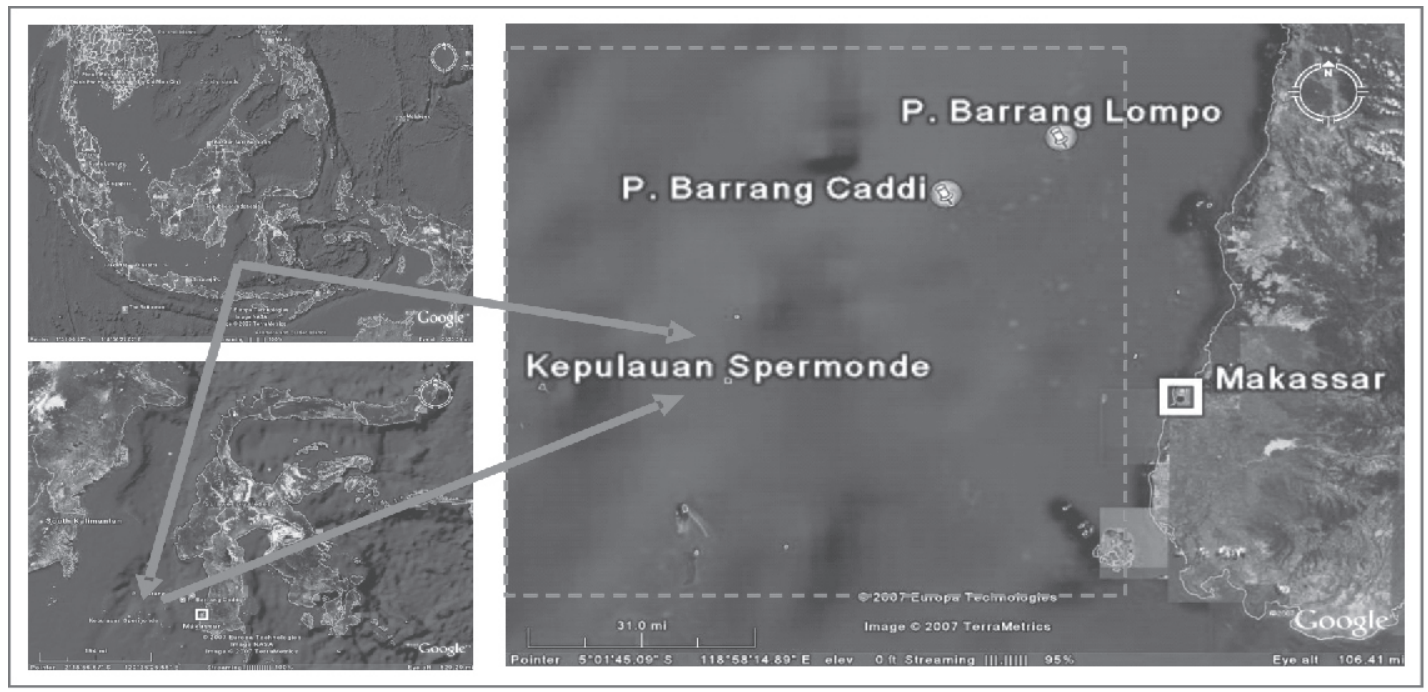

Keterangan :

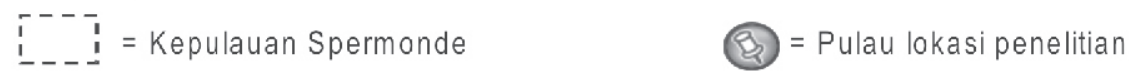

(Sumber : Google earth)

(Source : Google earth)

\section{Gambar 1. Lokasi Riset di Kepulauan Spermonde Provinsi Sulawesi Selatan (Sumber : Google earth)}

Figure1. Research Location in Spermonde Islands, South Sulawesi Province (Source : Google earth)

metode yang digunakan lebih dikenal dengan analisis bioekonomi.

Data ekonomi yang dikumpulkan adalah data harga dan biaya yang kemudian dikonversi dari nilai nominal ke riil menggunakan indeks harga konsumen. Konversi ini bertujuan untuk menghilangkan pergerakan harga yang tidak normal akibat adanya krisis moneter dan laju inflasi sehingga dapat diperoleh parameter ekonomi sumberdaya ikan karang hidup konsumsi. Data biologi yang dikumpulkan adalah data produksi dan effort. Data effort ini diperoleh melalui total effort yang dipergunakan di Perairan Spermonde untuk memanfaatkan ikan karang hidup konsumsi yaitu pancing dan bubu. Untuk mengetahui alat tangkap dominan digunakan fishing power index. Dari standarisasi effort dapat ditentukan total effort yang digunakan di perairan Spermonde. Dari data biologi berupa produksi dan effort ini dapat dilakukan pendugaan parameter biologi dengan model CYP (merupakan inisial nama dari Clarke, Yoshimoto dan Polley). Parameter ekonomi dan parameter biologi inilah yang akan digunakan dalam analisis bioekonomi sehingga dapat diketahui optimasi pemanfaatan sumberdaya ikan karang konsumsi / LRFF di perairan Kepulauan Spermonde Provinsi Sulawesi Selatan. Kerangka pendekatan studi optimasi sumberdaya ikan karang hidup konsumsi di Sulawesi Selatan ini dapat dilihat pada Gambar 2.

\section{Model yang Digunakan}

Model yang digunakan adalah model surplus produksi. Model ini mengasumsikan bahwa stok ikan merupakan selisih antara laju pertumbuhan dengan laju penangkapan, yang 


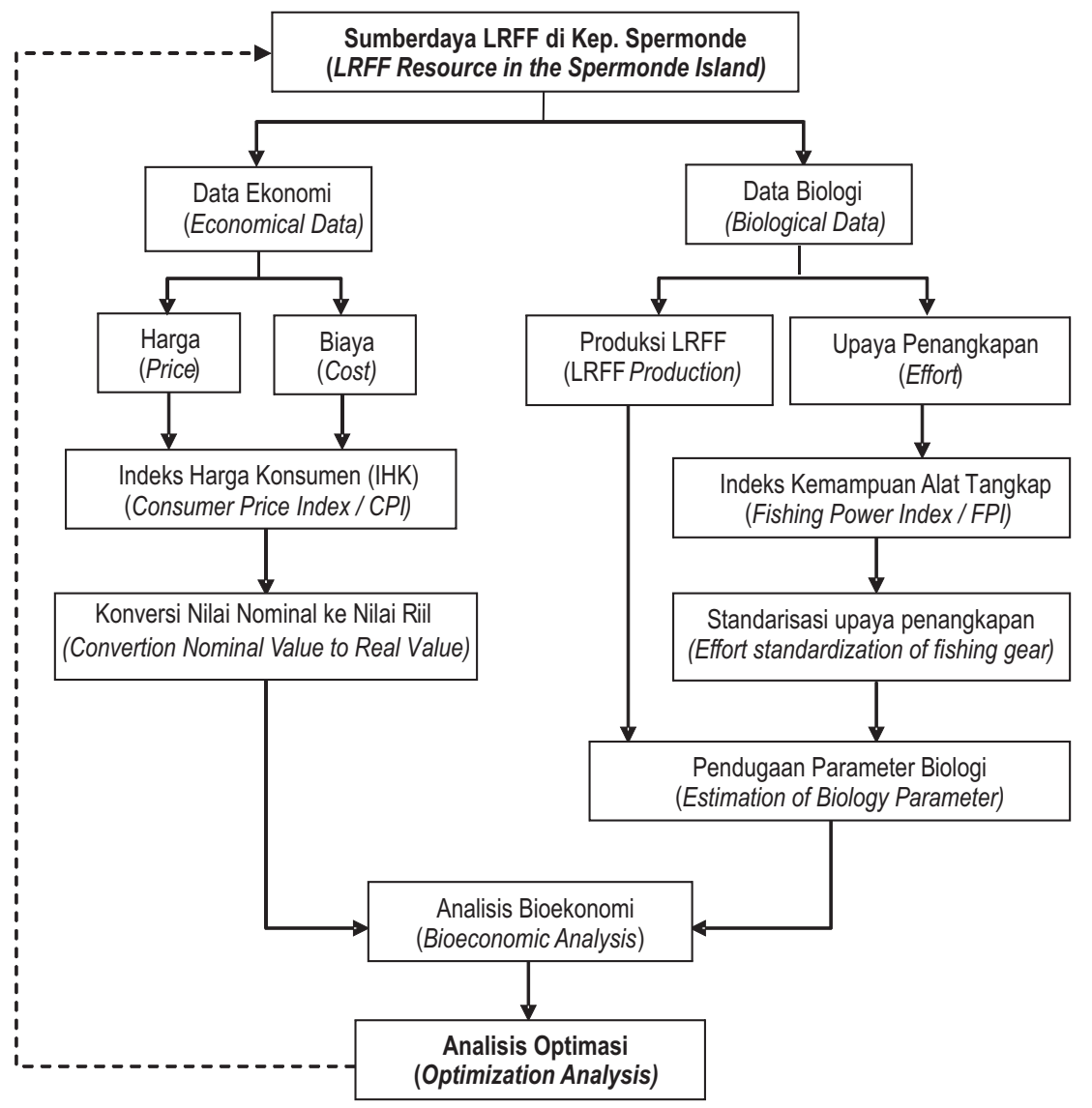

\section{Gambar 2. Kerangka Pendekatan Studi Optimasi Pemanfaatan Sumberdaya LRFF di Kepulauan Spermonde, Sulawesi Selatan, 2006}

Figure 2. Framework Approach of Optimalization Study LRFF Resource in the Spermonde Island, South Sulawesi, 2006

diacu dalam Fauzi (2004), yaitu :

$$
\frac{\partial X}{\partial t}=F(X)-h
$$

Keterangan :

$$
\begin{array}{cl}
F(X) & : \text { Laju pertumbuhan alami } \\
& \text { sumberdayaikan } \\
h \quad: & \text { Laju penangkapan }
\end{array}
$$

Untuk menggambarkan stok biomass ini menggunakan model logistik (Schaefer, 1954). Persamaan dari model logistik tersebut adalah

$$
\frac{\partial X}{\partial t}=r X\left(1-\frac{X}{K}\right)-h
$$

\section{Keterangan :}

$r \quad:$ laju pertumbuhan intrinsik

K : daya dukung lingkungan

Bentuk fungsi logistik adalah bentuk simetris di mana ada titik puncak kuadratik. Jika stok sumberdaya perikanan mulai dieksploitasi oleh nelayan, maka laju eksploitasi sumberdaya perikanan dalam satuan waktu tertentu diasumsikan merupakan fungsi dari input (effort) yang digunakan dalam menangkap ikan dan stok sumberdaya yang tersedia. Dalam fungsi hubungan itu dapat dituliskan (Fauzi, 2004) sebagai berikut : 


$$
h=H(E, X)
$$

Selanjutnya diasumsikan bahwa laju penangkapan linier terhadap biomass dan effort yaitu :

$$
h=q E X
$$

Keterangan :

q : Koefisien kemampuan penangkapan (catchability coefisien)

E : Upaya penangkapan

Asumsi kondisi keseimbangan (equilibrium) maka kurva tangkapan upaya lestari (yieldeffort-curve) dari fungsi di atas dapat ditulis (Fauzi, 2004) sebagai berikut :

$$
h=q K E-\left(\begin{array}{c}
q^{2} K \\
r
\end{array}\right) E^{2}
$$

Rezim pengelolaan sumbedaya perikanan yang umum digunakan adalah rezim pengelolaan maximum economic yield, maximum sustainable yield dan open access. Dalam penelitian sumberdaya ikan karang hidup konsumsi ini juga menggunakan rezim pengelolaan tersebut.

Jenis, Sumber dan Cara Pengumpulan Data

Data yang dibutuhkan dalam penelitian ini berupa data sekunder dan data primer. Data sekunder diperlukan untuk mengetahui historical data dalam pendugaan sumberdaya perikanan ikan karang hidup konsumsi. Data primer diperlukan untuk mengetahui existing condition masyarakat yang terlibat dalam pemanfaatan sumberdaya ikan karang di Kepulauan Spermonde. Data sekunder diperoleh dari Dinas Kelautan dan Perikanan Propinsi Sulawesi Selatan, Badan Pusat Statistik Sulawesi Selatan, Tempat Pelelangan Ikan (TPI), jurnal atau laporan ilmiah nasional maupun internasional, majalah perikanan dan ekonomi Departemen Kelautan dan Perikanan, internet melalui website FAO, IMA
(International Marine Association) serta beberapa instansi lainnya.

Metode pengambilan contoh (responden) yang digunakan dalam penelitian ini adalah purposive sampling. Penentuan responden di kedua wilayah yaitu Pulau Barrang Caddi dan Pulau Barrang Lompo, di mana responden tersebut merupakan nelayan yang mempunyai mata pencaharian menangkap ikan kerapu hitam (macan, tikus, bebek) dan kerapu merah (sunu) yang merupakan sumberdaya ikan karang hidup konsumsi dominan di perairan Kepulauan Spermonde.

\section{Metode Analisis Data}

Metode analisis data berdasarkan model pendekatan yang digunakan seperti yang telah diuraikan diatas terdiri dari metode untuk menduga parameter biologi dan parameter ekonomi dan metode untuk menduga nilai optimal pengelolaan sumberdaya ikan karang hidup konsumsi (Clark, 1990) berdasarkan tiga rezim pengelolaan.

\section{Pendugaan Parameter Sumberdaya Ikan Karang Hidup Konsumsi}

Dalam melakukan pendugaan parameter biologi, harus terlebih dahulu dilakukan standarisasi unit upaya mengingat dalam perikanan sering terjadi multi-species dan multi-gear. Standarisasi alat tangkap diperlukan untuk menyeragamkan satuan upaya penangkapan dari berbagai alat tangkap dengan menggunakan salah satu alat tangkap yang dominan dalam menangkap ikan sebagai alat tangkap standar.

Penentuan standarisasi unit upaya atau effort dalam penelitian ini digunakan jumlah trip per tahun dari dua alat tangkap yaitu bubu dan pancing sebagai alat tangkap kerapu dan sunu agar ikan tetap hidup. Alasan penggunaan trip sebagai unit upaya daripada jumlah alat adalah untuk mengurangi atau menghilangkan bias dari alat tangkap yang 
tidak beroperasi. Pemilihan kedua alat ini berdasarkan kondisi lapang, literatur dan masukan bahwa kedua alat tangkap ini merupakan alat tangkap dominan yang menangkap ikan karang hidup konsumsi (life reeffish for food) di lokasi penelitian.

Kedua alat tangkap ikan karang hidup ini memiliki kemampuan yang berbeda dalam menangkap ikan sehingga perlu dilakukan standarisasi effort. Indeks daya tangkap yang diukur berdasarkan rasio CPUE dari alat tangkap j (Ujt) terhadap alat tangkap standar pada waktu $t$ (Ust). Standarisasi effort ini menggunakan data yang tersedia dari tahun 1989 sampai 2003. Data ini dianggap telah mencukupi karena salah satu syarat dalam pemodelan bioekonomi adalah sedapat mungkin menggunakan data selama 15 tahun (Fauzi, 2004). Standarisasi effort ini menggunakan formula yang diacu dalam Fauzi (2002):

$$
\psi_{j t}=\frac{U_{j t}}{U_{s t}}
$$

Keterangan:

$\psi_{j t}=$ indeks daya tangkap j pada waktu $\mathrm{t}$

Ujt = CPUE dari alat tangkap $\mathrm{j}$ pada waktu t

Ust = CPUE dari alat tangkap standar pada waktu $t$

Penelitian ini menggunakan teknik estimasi parameter biologi dari model surplus produksi yaitu melalui pendugaan koefisien yang dikembangkan oleh Clarke, Yoshimoto, dan Polley (1992) atau sering dikenal dengan metode CYP yang diacu dalam Fauzi (2004). Persamaan CYP dalam bentuk matematis dapat ditulis sebagai berikut :

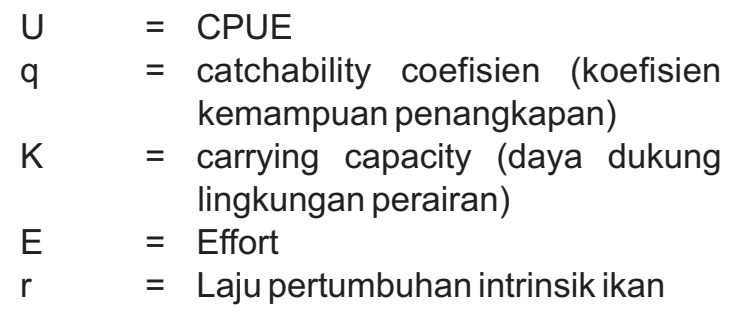

Dengan meregresikan hasil tangkap per unit input (effort) yang dilambangkan dengan $U$ pada periode $t+1$ dan dengan $U$ pada periode $t$, serta penjumlahan input pada periode $t$ dan $t+1$, akan diperoleh koefisien $r$, $q$ dan $\mathrm{K}$ secara terpisah. Selanjutnya setelah disederhanakan persamaan (2) dapat diestimasikan dengan OLS (Tinungki, 2005) melalui:

Sehingga nilai parameter $\mathrm{r}$, $\mathrm{q}$ dan $\mathrm{K}$ dapat

$$
\operatorname{Ln}\left(U_{t+1}\right)=\alpha+\beta \cdot \ln \left(U_{t}\right)+\gamma \cdot\left(E_{t}+E_{t+1}\right)
$$

diperoleh melalui persamaan berikut (Nababan, 2006):

$$
\left.\begin{array}{rl}
r & =\frac{2 \cdot(1-\beta)}{(1+\beta)} \\
q & =-\gamma \cdot(2+r) \\
K & =\frac{e^{\alpha \cdot(2+r) /(2 r)}}{q}
\end{array}\right\}
$$

\section{Pendugaan Nilai Optimal Sumberdaya LRFF}

Pendugaan nilai optimal pengelolaan sumberdaya ikan karang hidup konsumsi di perairan Kepulauan Spermonde pada rejim pengelolaan maximum economic yield (sole owner), maximum sustainable yield dan open access.

$$
\ln \left(U_{t+1}\right)=\frac{2 r}{(2+r)} \ln (q K)+\frac{(2-r)}{2+r} \ln \left(U_{t}\right)-\frac{q}{(2+r)}\left(E_{t}+E_{t+1}\right)
$$


1. Kondisi MEY (Maximum Economic Yield)

Pengelolaan perikanan pada kondisi MEY juga dikenal dengan rejim pengelolaan Sole Owner (Fauzi, 2004). Manfaat ekonomi dari ekstraksi sumberdaya ikan pada kondisi MEY yaitu :

$$
\pi=p \cdot\left(q K E\left(1-\frac{q}{r} E\right)\right)-c E
$$

Sedangkan untuk mengetahui tingkat upaya penangkapan yang optimal, maka manfaat ekonomi diatas diturunkan terhadap $\mathrm{E}$ menjadi

$$
E^{*}=\frac{r}{2 q}\left(1-\frac{c}{p q K}\right)
$$

Dengan tingkat panen optimal sebesar :

$$
h^{*}=\frac{r K}{4}\left(1+\frac{c}{p q K}\right)\left(1-\frac{c}{p q K}\right)
$$

Dengan tingkat biomass optimal sebesar :

$$
x^{*}=\frac{h}{q \cdot E}
$$

Dengan mensubtitusikan persamaan (11) dan persamaan (12) ke dalam persamaan (10), akan diperoleh manfaat (rente) ekonomi yang optimal.

\section{Kondisi MSY (Maximum Sustainable Yield)}

Manfaat ekonomi dari ekstraksi sumberdaya ikan pada kondisi pengelolaan MSY yaitu :

$$
\pi=p \cdot h_{M S Y}-c \cdot E_{M S Y}
$$

Menggunakan hasil dari persamaan (4) terhadap effort (E) akan menghasilkan :

$$
E_{M S Y}=\frac{r}{2 \cdot q}
$$

Dengan tingkat panen lestari sebesar :

$$
h_{M S Y}=\frac{r \cdot K}{4}
$$

Dengan tingkat biomas lestari sebesar :

$$
x_{M S Y}=\frac{r}{2 \cdot q}
$$

Dengan mensubtitusikan persamaan (15) dan persamaan (16) ke dalam persamaan (14), akan diperoleh manfaat (rente) ekonomi yang lestari.

\section{Kondisi Open Access (OA)}

Manfaat ekonomi dari ekstraksi sumberdaya ikan pada kondisi open access yaitu:

$$
\pi=p \cdot h_{O A}-c \cdot E_{O A}
$$

Menggunakan hasil dari persamaan (3.8) terhadap effort (E) akan menghasilkan :

$$
E_{O A}=\frac{r}{q}\left(1-\frac{c}{p \cdot q \cdot K}\right)
$$

Dengan tingkat panen maksimal sebesar :

$$
h_{O A}=\left(\frac{r \cdot c}{p \cdot q}\right)\left(1-\frac{c}{p \cdot q \cdot K}\right)
$$

Dengan tingkat biomas maksimal sebesar :

$$
x_{O A}=\frac{c}{p \cdot q}
$$

Dengan mensubtitusikan persamaan (18) dan persamaan (19) ke dalam persamaan (17), akan diperoleh manfaat (rente) ekonomi yang maksimal.

\section{HASIL DAN PEMBAHASAN}

\section{Pendugaan Parameter Sumberdaya Ikan Karang Hidup Konsumsi}

Produksi ikan yang digunakan dalam perhitungan potensi sumberdaya adalah kerapu dan sunu yang merupakan jenis ikan karang hidup konsumsi dominan yang tertangkap oleh alat tangkap bubu dan pancing. Data produksi dan upaya penangkapan (effort) dikumpulkan dari 
Tabel1. Produksi dan Effort Ikan Karang Konsumsi Hidup (LRFF) di Sulawesi Selatan, 1989-2003

Table 1. Production and Effort of Life Reef Fish for Food in South Sulawesi, 1989-2003

\begin{tabular}{crrrr}
\hline \multirow{2}{*}{ Tahun / Year } & \multicolumn{2}{c}{ Produksi / Production } & \multicolumn{2}{c}{ Upaya / Effort (trip) } \\
\cline { 2 - 5 } & Bubu / Trap & Pancing / Hook & Bubu / Trap & Pancing / Hook \\
\hline 1989 & 243,8 & 693,0 & 97.696 & 1.273 .526 \\
1990 & 194,7 & 672,7 & 72.403 & 1.199 .758 \\
1991 & 222,6 & 667,0 & 87.531 & 1.136 .121 \\
1992 & 307,4 & 711,4 & 98.106 & 1.174 .477 \\
1993 & 221,4 & 658,3 & 81.623 & 1.126 .410 \\
1994 & 219,1 & 901,7 & 72.083 & 1.224 .049 \\
1995 & 227,7 & $1.449,0$ & 67.034 & 1.233 .358 \\
1996 & 282,9 & $1.369,0$ & 72.179 & 1.162 .890 \\
1997 & 252,3 & 936,9 & 63.685 & 1.047 .741 \\
1998 & 237,9 & $1.159,4$ & 47.083 & 1.024 .425 \\
1999 & 272,9 & $1.312,1$ & 51.193 & 1.009 .892 \\
2000 & 156,6 & $1.186,7$ & 34.903 & 931.080 \\
2001 & 157,4 & $1.134,3$ & 31.360 & 737.833 \\
2002 & 112,8 & $1.348,5$ & 39.847 & 826.651 \\
2003 & 154,4 & $1.134,3$ & 42.901 & 850.665 \\
\hline
\end{tabular}

Sumber : TPI Paotere Sulawesi Selatan, Dinas Perikanan dan Kelautan Provinsi Sulawesi Selatan (1990-2004), BPS Provinsi Sulawesi Selatan dan sumber lainnya.

Source : TPI Paotere South Sulawesi, Marine and Fisheries Services of South Sulawesi Province (1990-2004), Central Bureau of Statistics, South Sulawesi and others source.

berbagai sumber seperti data TPI, Dinas Kelautan dan Perikanan Sulawesi Selatan, BPS Provinsi Sulawesi Selatan dan berbagai sumber-sumber ilmiah lainnya. Data produksi dan effort yang digunakan dalam penangkapan ikan karang hidup konsumsi dalam analisis di Provinsi Sulawesi Selatan dari tahun 1989 - 2003 dapat dilihat pada Tabel 1.

\section{Standarisasi Upaya Penangkapan}

Sebelum mengetahui total effort maka perlu diketahui alat tangkap yang menjadi standar, mengetahui fishing power index atau FPI dari alat tangkap yang akan distandarisasi dan standarisasi upaya penangkapan (effort). Dalam perhitungan perlu diketahui salah satu alat tangkap yang paling dominan dalam operasi penangkapan untuk dijadikan standar dalam menyeragamkan jumlah upaya penangkapan (effort) yang digunakan terhadap sumberdaya ikan karang hidup konsumsi tersebut. Alat tangkap standar yang digunakan dalam penelitian ini adalah bubu, mengingat alat tangkap bubu ini mempunyai nilai proporsi tangkapan lebih besar jika dibandingkan dengan pancing.

Fishing Power Index (FPI) adalah tingkat kemampuan suatu alat tangkap dalam menangkap ikan atau suatu jenis ikan tertentu dalam waktu dan daerah tertentu pula. Perhitungan FPI diperlukan jika alat tangkap yang mengeksploitasi sumberdaya ikan atau suatu jenis ikan tertentu jumlahnya lebih dari satu.

Standarisasi effort atau upaya penangkapan adalah menyeragamkan besarnya nilai upaya penangkapan beberapa jenis alat tangkap ke dalam satuan jenis upaya alat tangkap tertentu yang dijadikan standar. Standarisasi effort diperoleh dengan mengalikan antara FPI dengan effort masing- 
Tabel 2. Standarisasi Effort Alat Tangkap yang Digunakan di Sulawesi Selatan, 2006

Table 2. Effort Standardization of Fishing Gear Used in South Sulawesi, 2006

\begin{tabular}{cccccccc}
\hline \multirow{2}{*}{$\begin{array}{c}\text { Tahun I } \\
\text { Year }\end{array}$} & \multicolumn{9}{c}{ Bubu / Trap } & \multicolumn{3}{c}{ Pancing / Hook } & \multirow{2}{*}{$\begin{array}{c}\text { TES } \\
\text { nypl }\end{array}$} & $\begin{array}{c}\text { Upaya I } \\
\text { Effort (trip) }\end{array}$ & Std Effort & FPI & $\begin{array}{c}\text { Upaya I } \\
\text { Effort (trip) }\end{array}$ & Std Effort & (Trip) \\
\cline { 2 - 7 } & $(1)$ & $(2)$ & $(3)$ & $(4)$ & $(5)$ & $(6)$ & $(7)$ \\
\hline 1989 & 1 & 97.696 & 97.696 & 0,218056 & 1.273 .526 & 277.700 & 375.396 \\
1990 & 1 & 72.403 & 72.403 & 0,208506 & 1.199 .758 & 250.157 & 322.560 \\
1991 & 1 & 87.531 & 87.531 & 0,230854 & 1.136 .121 & 262.278 & 349.809 \\
1992 & 1 & 98.106 & 98.106 & 0,193313 & 1.174 .477 & 227.042 & 325.148 \\
1993 & 1 & 81.623 & 81.623 & 0,215458 & 1.126 .410 & 242.694 & 324.317 \\
1994 & 1 & 72.083 & 72.083 & 0,242356 & 1.224 .049 & 296.656 & 368.739 \\
1995 & 1 & 67.034 & 67.034 & 0,345869 & 1.233 .358 & 426.580 & 493.614 \\
1996 & 1 & 72.179 & 72.179 & 0,300360 & 1.162 .890 & 349.286 & 421.465 \\
1997 & 1 & 63.685 & 63.685 & 0,225714 & 1.047 .741 & 236.490 & 300.175 \\
1998 & 1 & 47.083 & 47.083 & 0,223987 & 1.024 .425 & 229.458 & 276.541 \\
1999 & 1 & 51.193 & 51.193 & 0,243724 & 1.009 .892 & 246.135 & 297.328 \\
2000 & 1 & 34.903 & 34.903 & 0,284070 & 931.080 & 264.492 & 299.395 \\
2001 & 1 & 31.360 & 31.360 & 0,306296 & 737.833 & 225.995 & 257.355 \\
2002 & 1 & 39.847 & 39.847 & 0,576256 & 826.651 & 476.362 & 516.209 \\
2003 & 1 & 42.901 & 42.901 & 0,370501 & 850.665 & 315.172 & 358.073 \\
\hline
\end{tabular}

Keterangan / information:

$\mathrm{FPI}=$ Indeks kemampuan alat tangkap perikanan/ Fishing powerindex

Std Effort = Standarisasi effort alat tangkap/Effort standardization of fishing gear

TES = Total standarisasi effort alat tangkap/Total effort standardization of fishing gear

masing alat. Standar effort untuk bubu pada kolom 3 merupakan perkalian antara FPI bubu pada kolom 1 dan effort bubu pada kolom 2. Standar effort untuk pancing pada kolom 6 merupakan perkalian antara FPI pancing pada kolom 4 dan effort pancing pada kolom 5 . Total effort pada kolom 7 merupakan penjumlahan antara standar effort bubu dan standar pancing (Tabel 2). Total effort hasil standarisasi ini yang akan digunakan dalam perhitungan analisis bioekonomi selanjutnya.

\section{Pendugaan Parameter Biologi Dengan Metode CYP}

Analisis surplus produksi dengan metode CYP (1992) dalam penelitian ini dilakukan dengan menggunakan data produksi dan effort hasil standarisasi tahunan selama 15 tahun mulai tahun 1989 - 2003. Rata-rata produksi tahunan dari kedua alat tangkap yang dioperasikan untuk menangkap sumberdaya LRFF di perairan Kepulauan Spermonde Sulawesi Selatan adalah 1.239,88 ton per tahun dengan rata-rata upaya penangkapan (effort) hasil standarisasi sebanyak 352.408 trip per tahun. Jumlah trip ini telah distandarisasi sesuai dengan fishing power index masing-masing alat tangkap. Nilai CPUE total menunjukkan besaran produksi per unit upaya penangkapan dalam hal ini adalah trip. CPUE total diperoleh dari total produksi dibagi dengan total effort (jumlah trip beroperasi yang telah distandarisasi).

Pada Tabel 3, pendugaan parameter biologi dengan menggunakan metode CYP diperlukan nilai logaritma CPUE pada waktu $\mathrm{t}+1$ dan logaritma CPUE pada saat $\mathrm{t}$ serta jumlah effort pada waktu $t$ dan $t+1$. Dengan menggunakan OLS atau regresi : $L n$ CPUE $t+1$ (kolom 2) sebagai Y, Ln CPUE t (kolom 3) 
10 Optimasi Pemanfaatan Sumberdaya.... Sulawesi selatan (Benny O.B dan Yesi D.S)

Tabel 3. Input untuk Analisis Bioekonomi dengan Model CYP di Sulawesi Selatan, 2006 Table 3. Input for Bioeconomic Analysis with CYPModel in South Sulawesi, 2006

\begin{tabular}{cccc}
\hline CPUE Total & LN CPUE t+1 & LN CPUEt & Et + Et+1 \\
\hline$(1)$ & $(2)$ & $(3)$ & $(4)$ \\
\hline 0,00250 & $-5,9185$ & $-5,9933$ & 697955,9204 \\
0,00269 & $-5,9744$ & $-5,9185$ & 672369,0647 \\
0,00254 & $-5,7657$ & $-5,9744$ & 674957,0901 \\
0,00313 & $-5,9099$ & $-5,7657$ & 649464,5282 \\
0,00271 & $-5,7960$ & $-5,9099$ & 693055,4574 \\
0,00304 & $-5,6849$ & $-5,7960$ & 862352,5961 \\
0,00340 & $-5,5418$ & $-5,6849$ & 915079,1470 \\
0,00392 & $-5,5311$ & $-5,5418$ & 721640,3432 \\
0,00396 & $-5,2878$ & $-5,5311$ & 576716,0785 \\
0,00505 & $-5,2343$ & $-5,2878$ & 573869,2260 \\
0,00533 & $-5,4066$ & $-5,2343$ & 596722,9791 \\
0,00449 & $-5,2945$ & $-5,4066$ & 556749,8577 \\
0,00502 & $-5,8672$ & $-5,2945$ & 773564,6293 \\
0,00283 & $-5,6271$ & $-5,8672$ & 874282,7146 \\
0,00360 & & & \\
\hline
\end{tabular}

Tabel 4. Parameter Biologi LRFF di Sulawesi Selatan, 2006

Table 4. Biology Parameters of The LRFF in South Sulawesi, 2006

\begin{tabular}{lcr}
\hline \multicolumn{1}{c}{ Parameter Biologi / Biology parameter } & Simbol / Symbol & Nilai / Value \\
\hline Tingkat Pertumbuhan Individu Alami / Individual Growth Rate & $\mathrm{r}$ & 0,5328888 \\
Koefisien Kemampuan Tangkap / Catchability Coefficient & $\mathrm{q}$ & 0,0000007 \\
Daya Dukung Lingkungan Perairan (Ton) / Carrying Capacity & $\mathrm{K}$ & $8.307,22$ \\
\hline
\end{tabular}

sebagai X1 dan Et + Et+1 (kolom 4) sebagai $\mathrm{X} 2$.

Hasil OLS dari Tabel 3 dengan menggunakan shazam dan microsoft excell diperoleh nilai $\alpha=-2,1552170, \beta=0,5792245$ dan $\gamma=-0,0000003$ sehingga perairan adalah $8.307,22$ ton. Nilai-nilai dari parameter biologi dari r, q dan $\mathrm{K}$ tersebut dapat dilihat pada Tabel 4.

Pada Tabel 4 diketahui parameter biologi LRRF maka dilakukan analisis kontras untuk membandingkan antara produksi aktual

$$
\mathrm{Y}=-2,1552170+0,5792245 \cdot \mathrm{X}_{1}-0,0000003 \cdot \mathrm{X}_{2}
$$

Dari nilai-nilai $(\alpha, \beta, y)$ yang diperoleh tersebut kemudian dimasukkan ke dalam persamaan (2) sehingga dapat diduga tingkat pertumbuhan alami sebesar 0,5328888, koefisien kemampuan tangkap sebesar 0,0000007 dan daya dukung lingkungan / dan produksi lestari berguna untuk menunjukkan tingkat eksploitasi sumberdaya ikan karang hidup konsumsi yang telah terjadi. Untuk memperoleh fungsi produksi lestari sumberdaya ikan karang hidup konsumsi di perairan Spermonde, Sulawesi Selatan maka 


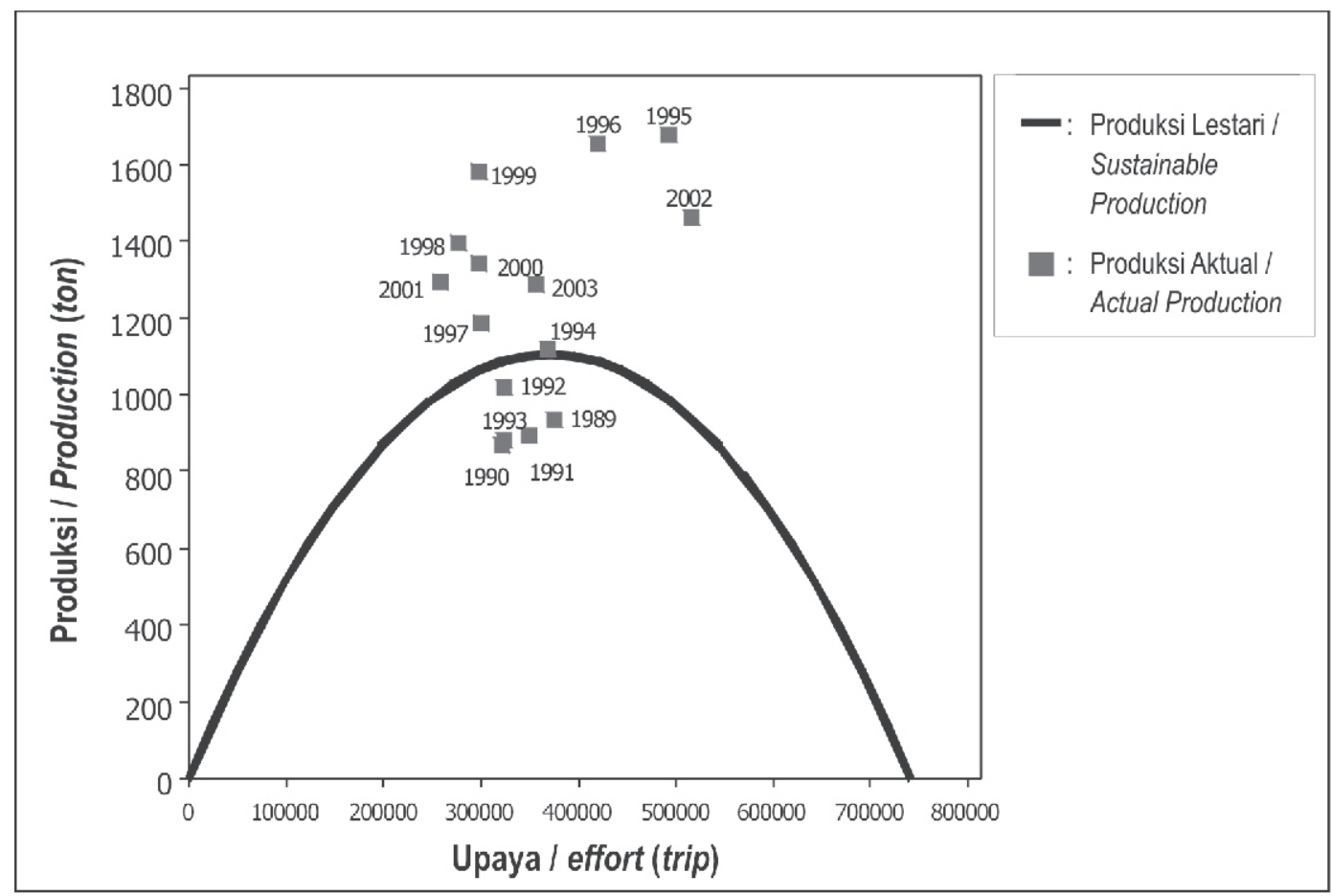

Gambar 3. Perbandingan Produksi Lestari dan Produksi Aktual dengan Tingkat Effort yang Sama

Figure 3. Comparison Between Sustainable Production and Actual Production at The Same Level of Effort

digunakan formula produksi lestari sumberdaya yang diacu dalam Fauzi (2004) yaitu :

$$
h_{t}=q K E_{t}\left(1-\frac{q E_{t}}{r}\right)
$$

dimana Et = Effort aktual pada tahun $\mathrm{t}$ $\mathrm{s}$ e d a $\mathrm{n} \mathrm{g} \mathrm{k} \mathrm{a} \mathrm{n}$ parameter biologi menggunakan nilai r, q dan K dari Tabel 4 maka diperoleh yaitu:

$$
h_{t}=0,0596 \cdot E_{t}\left(1-0,00000135 \cdot E_{t}\right)
$$

Dengan menggunakan fungsi produksi lestari tersebut dapat diketahui tingkat produksi lestari (ht) sumberdaya perikanan dari effort yang dilakukan setiap tahun dan dapat dilihat pada Gambar 3.

Dari Gambar 3 terlihat bahwa tingkat produksi aktual yang dihasilkan jauh lebih tinggi dibandingkan tingkat produksi lestari yang seharusnya sejak tahun 1995 (ditunjukkan oleh banyaknya produksi aktual di atas garis produksi lestarinya). Tingkat produksi aktual melonjak tinggi semenjak tahun 1995 sampai dengan tahun 2003, hal ini terjadi karena upaya penangkapan yang dilakukan oleh nelayan juga meningkat tajam akibat semakin tingginya permintaan dunia terhadap produk ikan karang hidup konsumsi dan semakin meningkatnya harga pembelian dari produsen. Semakin tinggi produksi aktual yang diusahakan (melebihi kondisi optimal) akan mengakibatkan terkurasnya sumberdaya perikanan sehingga tidak ada lagi yang dapat dimanfaatkan dalam jangka panjang oleh nelayan.

\section{Struktur Biaya Produksi dan Harga Ikan}

Penangkapan ikan karang hidup konsumsi (LRFF) dilakukan dengan dua alat 
tangkap yaitu bubu dan pancing. Untuk alat tangkap pancing dilakukan dengan armada lepa-lepa dan jololoro. Dalam pengoperasian setiap alat tangkap tersebut mengeluarkan biaya per trip yang berbeda-beda. Biaya per trip yang dikeluarkan tersebut yaitu untuk es, bensin, oli mesin, perbekalan, dan umpan. Total biaya per trip alat tangkap standar (bubu) adalah sebesar Rp.88.537,00.

Selain komponen biaya, komponen lain yang diperlukan untuk dianalisis dalam penelitian ini adalah komponen harga. Dalam model bioekonomi Copes, harga merupakan penentu dalam pengelolaan sumberdaya perikanan tangkap. Faktor harga ini sangat berpengaruh terhadap Total Revenue (TR) dan keuntungan yang diperoleh nelayan dari hasil tangkapannya. Komponen harga ini diperoleh dengan data sekunder melalui berbagai sumber akibat ketiadaan data harga ikan karang hidup konsumsi di tingkat produsen (nelayan) yang lengkap secara time series dari satu sumber. Sumber data tersebut diperoleh baik melalui jurnal atau laporan ilmiah nasional maupun internasional, majalah perikanan, ekonomi dan perdagangan, Badan Pusat Statistik, Dinas Kelautan dan Perikanan Sulawesi Selatan, Departemen Kelautan dan Perikanan, internet melalui website FAO, IMA (International Marine Association) dan berbagai sumber lainnya.

Komponen harga yang diperoleh dalam perdagangan ekspor ikan karang hidup ini lebih banyak dalam bentuk mata uang asing seperti dolar USA atau dolar Hongkong yang kemudian dikonversi ke dalam rupiah dengan kurs yang berlaku pada tahun harga tersebut. Data harga dari berbagai sumber ini terdiri dari berbagai jenis seperti harga di tingkat nelayan (produsen), harga di tingkat eksportir, harga di

Tabel 5. Harga Nominal Rata-Rata LRFF Pada Tingkat Nelayan di Sulawesi Selatan, 19892003 (Rp/kg)

Table 5. Average Nominal Price LRFFat Fishers'Level in South Sulawesi, 1989-2003 (Rp/kg)

\begin{tabular}{crrr}
\hline $\begin{array}{c}\text { Tahun/ } \\
\text { Year }\end{array}$ & $\begin{array}{c}\text { Harga/Price } \\
\text { (US\$/kg) }\end{array}$ & $\begin{array}{c}\text { Kurs } \\
\text { (US\$ 1 = Rp) }\end{array}$ & $\begin{array}{c}\text { Harga Nominal/ } \\
\text { Nominal Price (Rp/kg) }\end{array}$ \\
\hline 1989 & 5,90 & $1.848,58$ & $10.906,64$ \\
1990 & 5,60 & $1.848,58$ & $10.352,07$ \\
1991 & 5,60 & $1.954,17$ & $10.943,33$ \\
1992 & 3,33 & $2.032,58$ & $6.768,50$ \\
1993 & 3,00 & $2.089,42$ & $6.268,25$ \\
1994 & 3,33 & $2.164,17$ & $7.206,68$ \\
1995 & 6,70 & $2.252,83$ & $15.093,98$ \\
1996 & 9,40 & $2.347,17$ & $22.063,37$ \\
1997 & 10,20 & $2.951,75$ & $30.107,85$ \\
1998 & 9,91 & $9.874,58$ & $97.883,79$ \\
1999 & 8,75 & $7.808,92$ & $68.297,00$ \\
2000 & 9,25 & $8.534,42$ & $78.920,00$ \\
2001 & 8,19 & $10.265,67$ & $84.092,00$ \\
2002 & 7,51 & $9.261,17$ & $69.582,00$ \\
2003 & 9,58 & $8.571,17$ & $82.132,00$ \\
\hline
\end{tabular}

Sumber/Source:

Diolah dari / Processed data from : IMA-Hongkong (2001-2002), IMA-Indonesia et al. (2001), FMO-Hongkong (19962005), ADB (2003), APEC Fisheries Working Group, APEC \& ACIAR (2004), Koji_Y (1996-2006), Sadovy \& Liu (2004), Asia-Pacific Marine Finfish, IMA-Asia, Society for the Conservation of Reef Aggregations, Secretariat of the Pacific Community (1999, 2001, 2005), Padilla (2003), Muldoon (2005), Nature Conservancy, MAC \& TNC (2004), Lau \& ParryJones (1999), Graham (2001), Vitner (2004), BPS Provinsi Sulawesi Selatan / Central Bureau of Statistics Sulawesi Selatan (1989-2004) dan Bank Indonesia / Bank of Indonesia (http://www.bi.go.id tanggal akses 10 Januari 2006) 
Tabel 6. Harga Riil Rata-Rata LRFF Pada Tingkat Nelayan di Sulawesi Selatan, 1989-2003 (Rp/kg).

Table 6. Average Real Price LRFF at Fishers'Level in South Sulawesi, 1989-2003 (Rp/kg).

\begin{tabular}{cccc}
\hline $\begin{array}{c}\text { Tahun/ } \\
\text { Year }\end{array}$ & $\begin{array}{c}\text { Harga Nominal/ } \\
\text { Nominal Price } \\
\text { (Rp/kg) }\end{array}$ & $\begin{array}{c}\text { Indeks Harga Konsumen/ } \\
\text { Consumers Price Index } \\
(\mathbf{2 0 0 2}=\mathbf{1 0 0 )}\end{array}$ & $\begin{array}{c}\text { Harga Riil/ } \\
\text { Real Price } \\
\text { (Rp/kg) }\end{array}$ \\
\hline 1989 & $10.906,64$ & 19,78 & 55.128 \\
1990 & $10.352,07$ & 22,01 & 47.027 \\
1991 & $10.943,33$ & 24,30 & 45.039 \\
1992 & $6.768,50$ & 25,63 & 26.410 \\
1993 & $6.268,25$ & 28,27 & 22.176 \\
1994 & $7.206,68$ & 31,25 & 23.063 \\
1995 & $15.093,98$ & 34,23 & 44.096 \\
1996 & $22.063,37$ & 36,71 & 60.094 \\
1997 & $30.107,85$ & 64,04 & 47.012 \\
1998 & $97.883,79$ & 65,17 & 150.191 \\
1999 & $68.297,00$ & 77,29 & 88.361 \\
2000 & $78.920,00$ & 80,16 & 98.449 \\
2001 & $84.092,00$ & 89,38 & 94.080 \\
2002 & $69.582,00$ & 100,00 & 69.582 \\
2003 & $82.132,00$ & 106,59 & 77.057 \\
Rata-rata & $40.041,16$ & & $63.814,39$ \\
\hline
\end{tabular}

Sumber : Badan Pusat Statistik (2002) dan Bank Indonesia (http://www.bi.go.id tgl akses 10 Januari 2006)

Source : Central Bureau of Statistics (2002) and Bank of Indonesia (http://www.bi.go.id: January 10 $\left.{ }^{\text {th }}, 2006\right)$

negara tujuan, dan harga di tingkat konsumen Kemudian data harga ini dijustifikasi kembali dengan harga perkiraan yang diterima oleh nelayan dari tahun 1989 sampai tahun 2003. Harga yang diperoleh ini merupakan harga nominal tahunan yang diterima nelayan sebagai produsen dari tahun 1989-2003 dan dapat dilihat pada Tabel 5.

Salah satu masalah dalam penentuan harga adalah adanya pergerakan harga yang tidak normal akibat adanya krisis moneter dan laju inflasi. Untuk mengatasi ketidaknormalan pergerakan harga tersebut maka dilakukan penyesuaian dengan cara mengkonversi harga nominal yang diperoleh menjadi harga riil. Dalam mengkonversi harga nominal menjadi harga riil maka digunakan IHK atau Indeks Harga Konsumen yang dipublikasi oleh Badan Pusat Statistik (BPS) Provinsi Sulawesi Selatan. Indeks Harga Konsumen yang digunakan dengan tahun dasar 2002 untuk memperoleh harga riil dari tahun 1989-2003 yang dapat dilihat pada Tabel 6 .

Pada Tabel 6 di atas menunjukkan harga rata-rata ikan kerapu hidup atau ikan karang hidup konsumsi dari Sulawesi Selatan mengalami fluktuasi. Secara rata-rata, ikan karang hidup konsumsi atau ikan karang hidup konsumsi ini mengalami peningkatan harga dari tahun 1989-2003 sebesar $15 \%$ dengan harga riil atau $27 \%$ dengan harga nominal. Kenaikan harga tertinggi terjadi pada tahun 1998 yaitu 225,1 \% dengan harga riil atau $219,5 \%$ dengan harga nominal. Hal ini terjadi akibat krisis moneter yang terjadi di Indonesia pada tahun 1998. Tabel 6 juga menunjukkan harga rata-rata kerapu hidup atau ikan karang hidup konsumsi baik harga nominal maupun harga riil yang diperoleh. Selama periode tahun 1989-2003 rata-rata harga nominal ikan 
Tabel 7. Tingkat Biomas, Produksi, Upaya Optimal dan Keuntungan dari Berbagai Rejim Pengelolaan Perikanan LRFF di Sulawesi Selatan, 2006

Table 7. Biomass Rate, Production, Optimal Effort and Benefit from Various Management Regimes of The LRFF Fisheries in South Sulawesi, 2006

\begin{tabular}{lrrr}
\hline \multirow{2}{*}{ Parameter } & \multicolumn{3}{c}{ Pengelolaan Perikanan (Fisheries Management) } \\
\cline { 2 - 4 } & Sole Owner / MEY & MSY & Akses Terbuka / Open Access \\
\hline X (ton) & 5.120 & 4.154 & 1.933 \\
$\mathbf{h}^{*}$ (ton) & 1.047 & 1.107 & 790 \\
E* $^{*}$ (trip) & 284.792 & 371.128 & 569.584 \\
$\pi$ (Rp.) & 41.587 .148 .882 & 37.765 .171 .742 & 0 \\
\hline
\end{tabular}

karang hidup konsumsi di tingkat nelayan sebesar Rp.40.041,16 per kilogram sedangkan rata-rata harga riil adalah sebesar Rp.63.814,39 per kilogramnya.

Pendugaan Nilai Optimal Sumberdaya ikan karang hidup konsumsi di Kepulauan Spermonde

Penentuan tingkat optimal pemanfaatan sumberdaya ikan karang hidup konsumsi dilihat dari rezim maximum economic yield (MEY), maximum sustainable yield (MSY) dan akses terbuka. Nilai biomas optimal pada rezim maximum economic yield (MEY) adalah 5.120 ton, tingkat produksi optimal adalah 1.047 ton dan jumlah effort (trip) optimal yang diperbolehkan adalah 284.792 trip. Pada rezim maximum sustainable yield (MSY) biomas, produksi dan upaya lestari adalah berturut- turut 4.154 ton, 1.107 ton dan 371.128 trip. Rezim akses terbuka biomas maksimum hanya 1.933 ton, produksi maksimum yang dapat diperoleh sebesar 790 ton dan jumlah trip maksimum yang diperbolehkan 569.584 trip. Rente ekonomi yang diperoleh jika menerapkan rezim MEY adalah Rp 41.587.148.882, rezim MSY adalah Rp 37.765.171.742 dan kondisi akses terbuka (open access) tidak ada atau nol. Nilai-nilai dari bioekonomi ini dapat dilihat pada Tabel 7 .

Pada Gambar 4 dan Gambar 5 terlihat sangat jelas, perbandingan dari ketiga rejim pengelolaan perikanan untuk LRFF, dimana pada saat LRFF dikelola sole owner maka diperoleh hasil tangkapan dan rente yang lebih besar walaupun dengan effort yang lebih sedikit jika dibandingkan pada kondisi MSY dan open access. Bahkan secara jangka

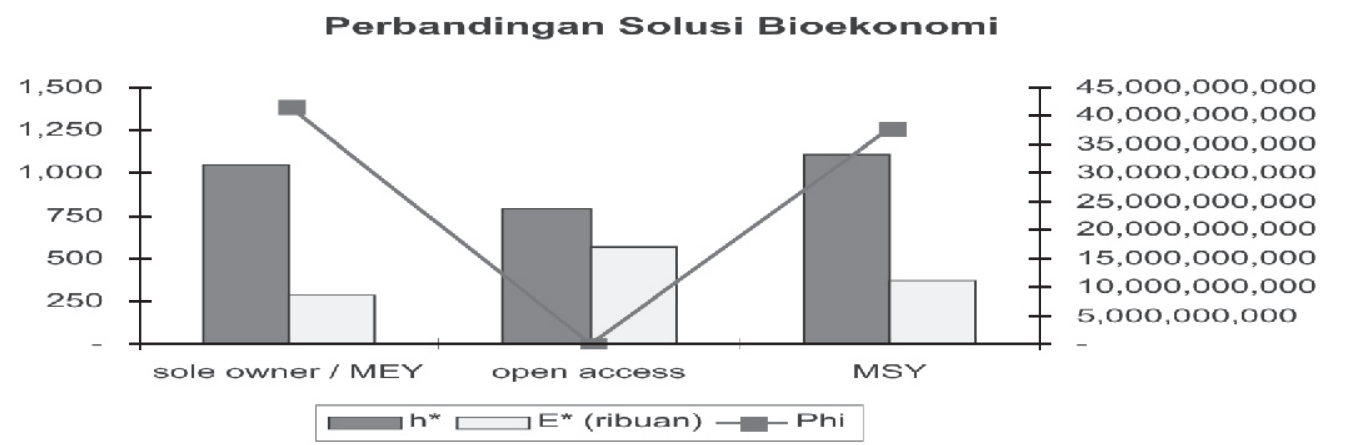

Gambar 4. Perbandingan Solusi Bioekonomi dari Ketiga Rejim Pengelolaan Sumberdaya LRFF di Sulawesi Selatan, 2006

Figure 4. Comparison of Bioeconomic Solution from Third Regimes of Resources LRFF Management in South Sulawesi, 2006 


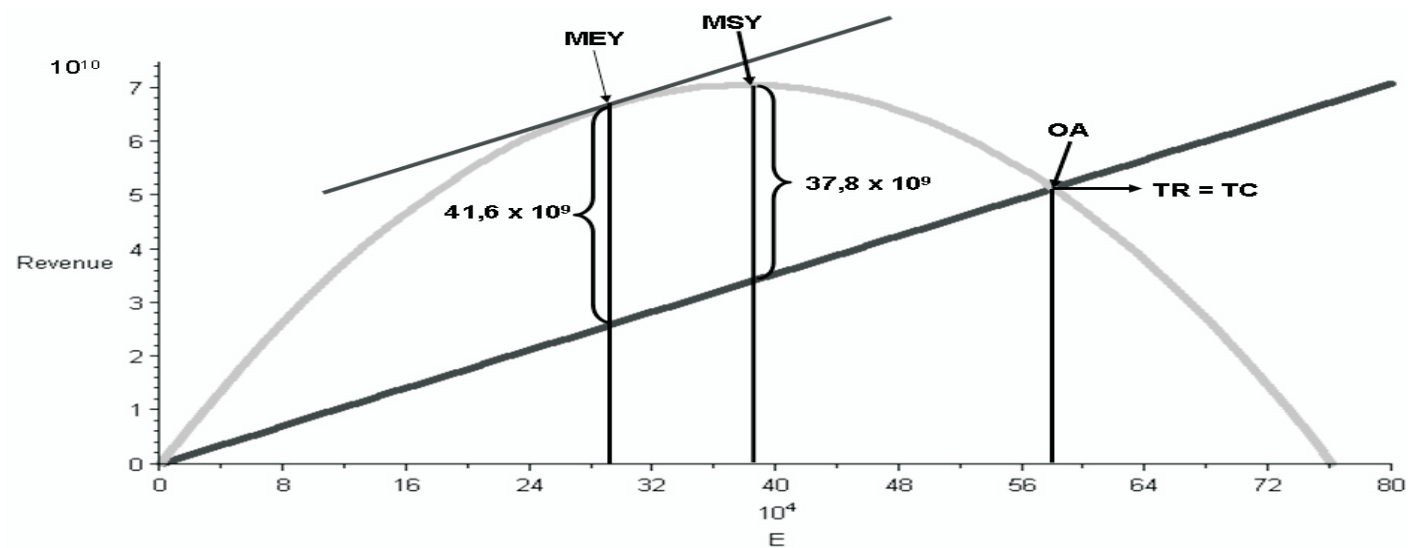

Gambar 5. Keseimbangan Bioekonomi Sumberdaya LRFF di Sulawesi Selatan, 2006

Figure 5. Bioeconomics Equilibrium of LRFFResources in South Sulawesi, 2006



Gambar 6. Perbandingan Produksi LRFF dalam Kondisi MEY, MSY, Open Access dan Aktual di Perairan Kepulauan Spermonde, Sulawesi Selatan, 2006

Figure 6. Comparison of LRFF Production in MEY, MSY, Open Access and Actual Conditions in Spermonde Island, South Sulawesi, 2006

panjang bilamana pengelolaan perikanan dengan kondisi MSY (maximum sustainable yield) masih dapat diperoleh rente ekonomi jika dibandingkan kondisi akses terbuka (open access).

Pada Gambar 6, terlihat tingkat produksi yang berbeda dari masing-masing kondisi pengelolaan hasil solusi bioekonomi dan rata- rata kondisi aktual. Rata-rata produksi pada kondisi aktual lebih tinggi dari setiap kondisi pengelolaan baik MEY, MSY dan open access. Oleh karena itu dapat dikatakan bahwa di perairan Kepulauan Spermonde telah terjadi over harvested dari sisi output atau produksi yang menyebabkan terjadinya biological overfishing dari setiap rejim pengelolaan. 


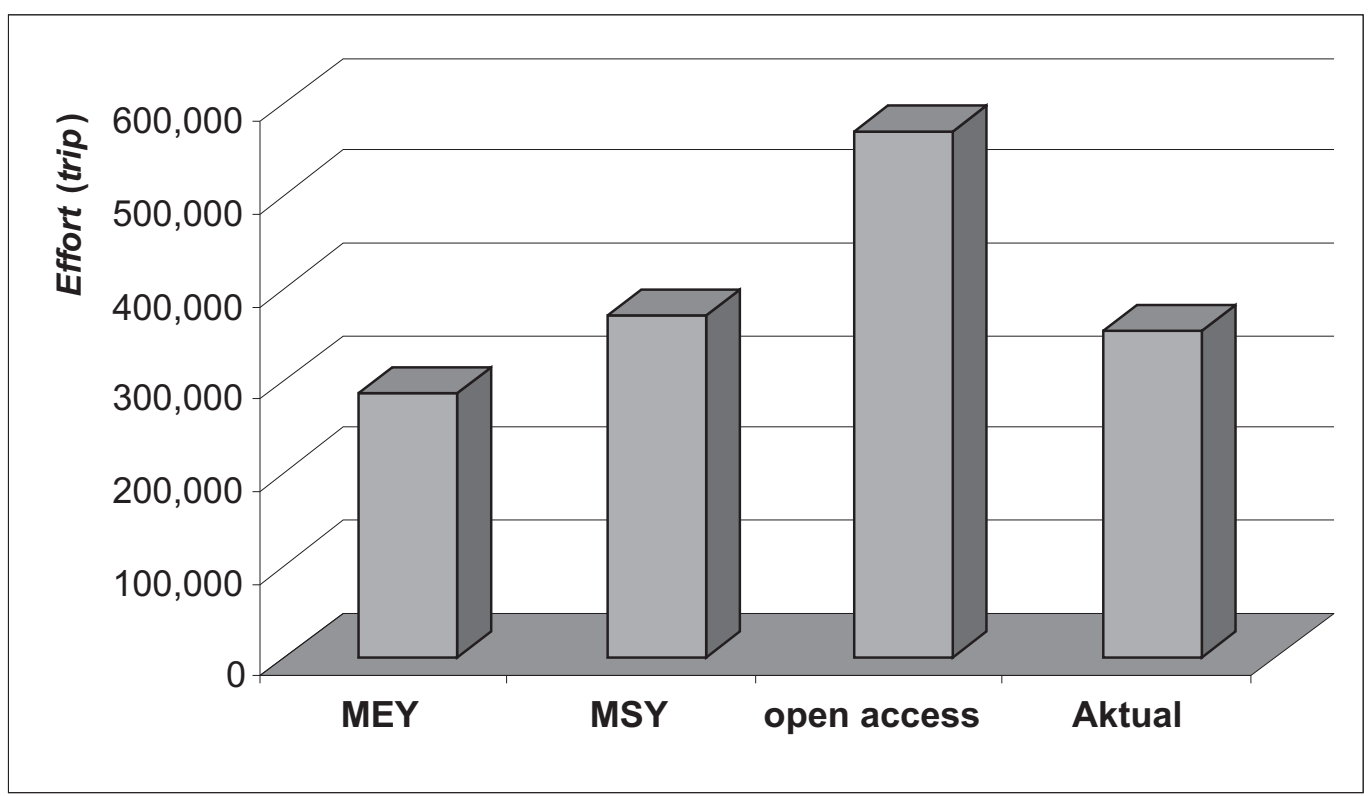

Gambar 7. PerbandinganTingkat Effort dalam Kondisi MEY, MSY, Open Access dan Aktual di Perairan Kepulauan Spermonde, Sulawesi Selatan, 2006

Figure 7. Comparison of Various Level Effort at MEY, MSY, Open Access and Actual Condition in Spermonde Island, South Sulawesi, 2006

Pada Gambar 7, terlihat effort rata-rata pada kondisi aktual di atas kondisi MEY namun masih berada di bawah kondisi MSY dan kondisi open access. Rata-rata effort aktual sudah melebihi satu setengah kali lipat dari kondisi optimal MEY. Tingkat effort yang semakin meningkat ini juga akan meningkatkan biaya operasional sehingga rente ekonomi yang diterima nelayan akan semakin menurun. Peningkatan rata-rata effort aktual ini pada akhirnya akan menuju economic overfishing. Gambar 6 dan Gambar 7, menunjukkan bahwa di perairan Kepulauan Spermonde, Sulawesi Selatan dalam pemanfaatan sumberdaya LRFF telah terjadi biological overfishing dari setiap rejim pengelolaan (MEY, MSY dan open access) dan economic overfishing dari rejim pengelolaan optimal MEY.

\section{KESIMPULAN}

1) Sumberdaya LRFF di perairan Kepulauan Spermonde, Sulawesi Selatan telah terjadi tangkap lebih (overfishing) sebesar $15,56 \%$ dari produksi optimal sole owner. Pada kondisi sole owner dimana tingkat effort dan produksi optimal yang dianjurkan sebesar 284.792 trip dan 1.047 ton/tahun, sedangkan rata-rata effort dan produksi aktual sebesar 352.408 trip dan $1.239,88$ ton/tahun.

2) Jumlah effort optimal (rejim MEY) dalam pemanfaatan sumberdaya LRFF di Kepulauan Spermonde adalah 284.972 trip/tahun dengan jumlah hasil tangkapan 1.047 ton/tahun

3) Rente atau surplus ekonomi yang diterima dari hasil analisis bioekonomi di perairan Kepulauan Spermonde, Sulawesi Selatan untuk ketiga rejim 
pengelolaan yaitu sole owner (MEY) sebesar 41.587.148.882 rupiah, MSY sebesar 37.765.171.742 rupiah dan open access tidak ada.

\section{SARAN}

1. Implementasi pengelolaan pada tingkat optimal penangkapan sumberdaya LRFF agar tidak terjadi overfishing yang pada akhirnya merugikan semua pihak. Implementasi pengelolaan ini dapat berupa kontrol terhadap input (effort) atau output (produksi) dengan instrumen ekonomi pengenaan pajak input maupun output. Pajak tersebut dapat digunakan dalam pemeliharaan MPA yang disepakati bersama dan penutupan kawasan pada waktu tertentu saat sumberdaya sedang bereproduksi.

2. Menghidupkan kembali kawasan konservasi laut yang pernah terbentuk pada tahun-tahun sebelumnya namun menurut masyarakat sudah tidak berfungsi lagi sampai saat ini.

3. Pembuatan peraturan (payung hukum) yang jelas dari tingkatan yang lebih tinggi (tidak sebatas peraturan desa) dan dapat diterima oleh berbagai pihak mengenai MPA di Kepulauan Spermonde dan pengawasan dari peraturan tersebut di lapangan.

\section{DAFTAR PUSTAKA}

Badan Pusat Statistik Provinsi Sulawesi Selatan. 2004. Sulawesi Selatan dalam Angka Tahun 2003. Provinsi Sulawesi Selatan: BPS.

Clark, CW. 1990. Mathematical Bioeconomics. The Optimal Management of Renewable Resources. 2nd ed. New York: Wiley-Interscience

Clarke, RP., Yoshimoto, SS., and Polley, SG. 1992. A Bioeconomic Analysis of the
North-Western Hawaiian Island Lobster Fishery. Marine Resources Economics $7(2): 115-140$.

Departemen Kelautan dan Perikanan. 2003. Country Status Overview 2001 tentang Eksploitasi dan Perdagangan dalam Perikanan Karang di Indonesia. Jakarta: DKP.

Fauzi, A. 2004. Ekonomi Sumber Daya Alam dan Lingkungan. Jakarta: PT. Gramedia Pustaka Utama.

Fauzi, A. 2002. A Note Surplus Production Model. Bogor: Institut Pertanian Bogor.

Nababan, B.O. 2006. Analisa Dampak Perdagangan Ikan Karang Hidup Konsumsi (Life Reef Fish for Food) Terhadap Sumberdaya Perikanan (Studi Kasus di Provinsi Sulawesi Selatan) (Tesis). Bogor: Institut Pertanian Bogor, Sekolah Pascasarjana.

Schaefer, M. 1954. Some Aspects of the Dynamics of Populations Important to Management of Commercial Marine Fisheries. Bull. Inter-Am. Trop. Tuna. Comm. (1) 27-56.

Tinungki, G. M. 2005. Evaluasi Model Produksi Surplus Dalam Menduga Hasil Tangkapan Maksimum Lestari Untuk Menunjang Kebijakan Pengelolaan Perikanan Lemuru Di Selat Bali. (Disertasi). Bogor: Institut Pertanian Bogor. Sekolah Pascasarjana. 